\title{
What is Behind the Prosperous Art Market in China?
}

\author{
Fanyu Zhou ${ }^{1}$, Ralf Sensel ${ }^{2}$ \\ ${ }^{1,2}$ College of Humanities and Sciences of Northeast Normal University, Changchun, China \\ 1322@163.com
}

Key words: art market; corruption; money laundering; bribery

\begin{abstract}
The Chinese art market is flourishing at an incredibly high speed. The purpose of this paper is to lift the veil off the prosperity of the Chinese art market and to reveal what the underlying problems and the real reasons for the morbid development are. Interviews show that the Chinese art market is driven heavily by corruption and money laundering. A survey is conducted to probe the public's readiness to invest in Chinese art. Finally some recommendations are offered to deal with the problems and challenges associated with the Chinese art market.
\end{abstract}

\section{Introduction}

In the past decade of years, the Chinese art and antique market flourished as never before, seeing its peak in 2010 and 2011. Figure1 shows an incredible proportion of China's share in the global art market in 2012. Furthermore, the increase is historically unparalleled all over the world. According to a survey published by the Times Magazine in 2009, of the 200 world's greatest artists, none was Chinese. Nevertheless, their works are ostensibly traded at much higher prices than the works of their most famous counterparts.

What has contributed to the apparent explosion in the Chinese art market? How come China has become the world's number one art market without the world's well-known artists? It was reported by China's art market monitor Artron that "2010 and 2011 are not only the peak years" of the Chinese art market trade volume, but also the "year of the bubble". Although the transaction scale is tremendous, with a great number of sky-high prices, void trade and false business constitute a big proportion., ${ }^{, 1]}$

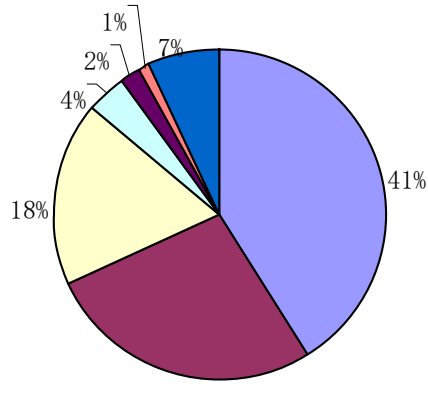

$27 \%$

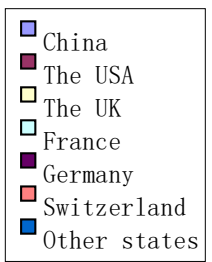

Figure 1. The global turnover of fine art in 2012 


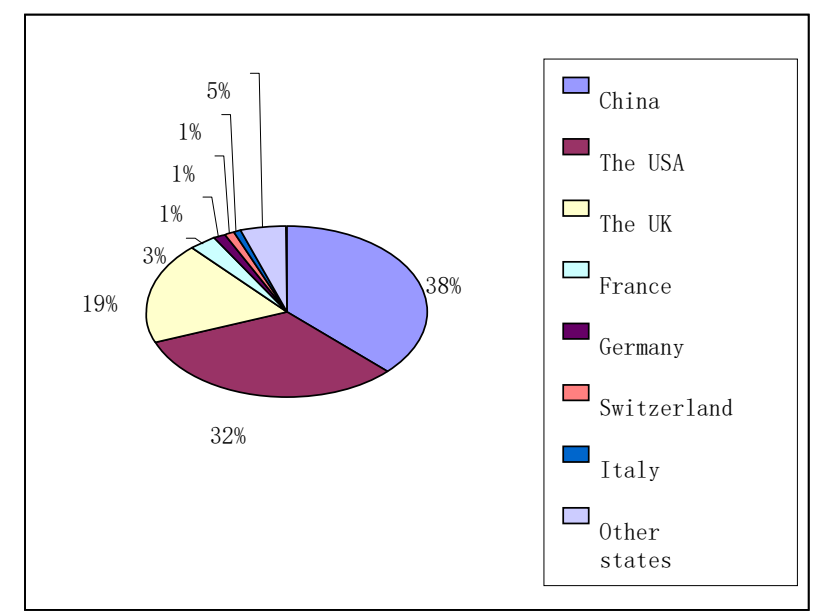

Figure 2. The global art auction market turnover in 2014

Table1. Total Turnovers of Chinese Art Auction from 2008 to 2015 (unit: million yuan)

\begin{tabular}{|l|l|}
\hline Years & Turnovers \\
\hline 2015 & $31,515,70$ \\
\hline 2014 & $34,768,25$ \\
\hline 2013 & $64,463.23$ \\
\hline 2012 & $63,271,40$ \\
\hline 2011 & $96,845.90$ \\
\hline 2010 & $59,652.51$ \\
\hline 2009 & $23,145.69$ \\
\hline 2008 & $20,420.03$ \\
\hline
\end{tabular}

Table1 reveals that the Chinese art auction market saw its 2011 turnover reaching a new high of RMB 96.8 billion Yuan. From 2010 to 2013, Chinese art market has been thriving at high speed, mainly because it took the advantages from China's real estate restraint policy, sluggish stock market and the fact that artworks function as the carrier for gift economy. However, in 2014 and 2015, the situation changed dramatically. Figure 2 shows that although China's art market has started to decline since 2012, it still maintains the top position in 2014. However, behind those big numbers, we are surprised to hear that "currently, the art auction market has such major hidden dangers: rampant art forgery, counterfeit auctions, related transactions, deal falsification and payment delay or refusal. These dangers are hampering the healthy development of the art auction industry.” [1]

Lifting the veil off the flourishing art market in China, we can see corruption, bribery and money laundering. Xiao Ping, a famous artist and former Nanking Museum Appraisal Consultant said that "in medium and small auction companies, $80 \%$ of the works of art are fake.” ${ }^{[2]}$

This raises the following questions: What makes the price of Chinese works of art and antiques appreciate hundreds of times within several years? What makes unknown Chinese artists' works much more "valuable" than those of the world's most famous artists? The answer is: Money laundering does. Sky-high works of art has become the best means to launder money, embezzle and bribe.

As shown below, there are quite a few problems in the Chinese art and antiques market. 


\section{The problems of the Chinese art and antiques market}

Sending gifts in order to obtain favor is not new and has a long history in China. Works of art and antiques have been a secret weapon among government officials' communication. "The bribery cases in the recent years have demonstrated that works of art and antiques are on the top of the list of assets, surpassing real estate., ${ }^{, 3]}$ Hence, works of art and antiques as means of bribery pose a challenge for legislation, jurisdiction and supervision departments across the country. Since March, 2013, Xi Jinping and his Administration have imposed the strictest anti-corruption regulations of the past 30 years. This is the one of the most important reasons why Chinese art market saw a decline since 2013 as revealed in figure 3. The Chinese art market has been cooling down since 2013, which coincided with China's combat of corruption, this confirms that Chinese art market is closely connected with corruption. However, this regulation is far from enough to control bribery and corruption, because there are many possible alternatives.

"The most common types of criminals who need to launder money are drug traffickers, embezzlers, corrupt politicians and public officials, mobsters, terrorists and con artists. ${ }^{,[4]}$ Since direct sending gifts to government officials is prohibited by law, the person in need come up with various alternatives to bribe or accept bribery. Money laundering and bribery are Siamese twins. The secret nature of embezzlement and bribery determines the close connection between corruption and money laundering. Money laundering is the extension of corruptive action. Art market is ideal for covering illegal activities. "In an industry that lacks much in the way of regulation and heavily relies upon privacy, it is no surprise that the sale and transfer of fine art is one of the world's most popular methods of money laundering. ${ }^{[5]}$ In China, the price of antiques and works of art is not given by an authority and there is no criterion for evaluation. The price is highly determined by how much the buyer is willing to pay. That leaves a possibility for manipulation and makes it difficult for anyone reviewing purchases, including the supervision department, to accuse a buyer of over-paying or under-paying. In international justice systems, regulatory bodies and police forces are inadequately equipped to detect and investigate such criminal activity. "Proceeds from various crimes can be easily laundered through the purchase of works of art thanks to a big loophole-a lack of awareness and regulation., ${ }^{[6]}$ Chinese art and antiques market share holds number one position all over the world, wherein money laundering plays a dominant role.

In recent years, one of the Chinese government's macro policies is to encourage culture industry. There is no strict regulation in the art market. The following rules are not enough to regulate the art market.

The Auction Law of China article 21: the auctioneer shall keep the identity of his client and vendee confidential if so requested. This confidential rule provides a safe island for money laundering.

The Anti-Money laundering Law of China stipulates that the obligations of reporting suspicious large-value transactions fall on only financial institutions and designated non-financial institutions. But fines or punishment on financial institutions for non-compliance have been insignificant. Chinese banks are weak in internal controls and have no corporate cultures for tackling money laundering. Obviously, the auction companies and other institutions specializing in money-laundering are not included in the list. Now there are more and more suspicious art transactions, now auditing seems to be the only way to investigate money laundering by art. No doubt that power is too limited. 


\section{Recommendations}

In auction market, the works of art should be priced by authoritative appraisers who should be responsible for their appraising report. If they give false appraising, their appraising license must be revoked and they can not work in art field for life. They should be given a severe punishment for malpractice.

At present, China's Anti-money laundering law only requires financial institutions and designated institutions to report large value and suspicious transactions. The people who want to launder money will definitely not make contact with the banks. The other institutions that have connections with the art market should be supervised. Auctions should be held publicly, and journalist should be present to report so that auctions can not be made secretly.

In order to prevent the works of art of absurdly high price from occurring frequently, heavy taxation on them might be an effective measure. Ladder taxation is a reasonable mode. The higher the price is, the more taxes should be levied.

\section{Conclusion}

Lifted the veil of its prosperity, Chinese art market is really problematic. Money laundering has ruined the Chinese art market which shows a morbid development at appalling speed. What we need to do before everything is to cut the connection between corruption and money laundering with art market. First, establish an authoritative appraising system and appraiser-liable principle to remove high-value fakes from the art market. Second, the scope of suspicious transaction report should be enlarged from financial institutes to art market. Third, the two parties to art transaction should pay tax based on the value of the subject.

\section{References}

[1]. http://amma.artron.net/report.php

[2]. http://jyfart.com/forum.php?mod=viewthread\&tid=17049\&extra=\&page=6

[3]. Sun Bing. 2012. Art market: A Surge of Dirty Money. China Economy Weekly. 1.P34-37.

[4]. Julia Layton: How Money Laundering Works. http:// money. Howstuff works. com/ money-launderring. $\underline{\mathrm{htm}}$

[5]. Daniel A. Schnapp. United States: Money Laundering and Art. Fox Rothschild. 22 May 2013.

[6]. Charlotte Burns and Melanie Gerlis. How Prevalent is Money Laundering in the Art World? News, Issue 246, May 2013.Published online: 13 May 2013. 